\title{
LA PALABRA DE DIOS EN LA FORMACIÓN DE LOS SACERDOTES Y LAS PERSONAS CONSAGRADAS
}

DOI: https://doi.org/10.52039/seminarios.v57i199-200.354

NuRia Calduch-Benages ${ }^{1}$

Esta reflexión nace a partir de mi participación como experta en la XII Asamblea Ordinaria del Sínodo de Obispos sobre la Palabra de Dios en la vida y en la misión de la Iglesia (Ciudad del Vaticano, 5-26 de octubre de 2008), y de la lectura de la exhortación apostólica post-sinodal Verbum Domini ${ }^{2}$.

Verbum Domini retoma el mismo mensaje a cuarenta y cinco años de distancia de la constitución dogmática sobre la divina revelación, Dei Verbum, del concilio Vaticano II, el considerado por muchos como el documento más importante del Concilio, porque toca los fundamentos de la fe de la Iglesia: la Palabra de Dios, su revelación y su transmisión a través de la tradición viva y la Sagrada Escritura $^{3}$. Con el paso del tiempo, el entusiasmo por la Palabra de Dios suscitado en el concilio se ha ido perdiendo a causa de la rutina, el descuido y la dejadez, lo cual ha generado algunas desviaciones (espiritualismo, cientifismo) y erradas interpretaciones (fundamentalismos) entre los fieles. Verbum Domini quiere colmar este déficit en la vida del pueblo de Dios, (re)colocando la Palabra de Dios al centro de la vida y la misión de la Iglesia.

En esta última exhortación apostólica Benedicto XVI ofrece a toda la Iglesia sus reflexiones y recomendaciones a partir de los documentos sinodales realizados por los obispos y demás participantes en el Sínodo de la Palabra. Su objetivo es «indicar algunas líneas fundamentales para revalorizar la Palabra divina en la vida de la Iglesia, fuente de constante renovación, deseando al mismo La

1. Profesora de la Pontificia Università Gregoriana (Roma) y experta del Sínodo de los Obispos sobre «La Palabra de Dios en la vida y la misión de la Iglesia».

2. El documento se presentó en la sala de prensa de la Santa Sede el 11 de noviembre de 2010, en la que intervinieron el Card. Marc Ouellet, prefecto de la Congregación para los Obispos y relator general del Sínodo de la Palabra; Mons. Nicola Eterovic, secretario general del Sínodo de los Obispos; su subsecretario, Mons. Fortunato Frezza, y el Card. Gianfranco Ravasi, presidente del Pontificio Consejo de la Cultura. Asimismo, durante los días 1-4 de diciembre de 2010 se celebró en la Pontificia Universidad Urbaniana de Roma un Congreso Internacional sobre la Verbum Domini organizado por la Federación Bíblica Católica (FEBIC), cuyo Presidente es Mons. Vincenzo Paglia, Obispo de Terni-Narni-Amelia.

3. Cf. G. Betori, Leggere la Bibbia nella Chiesa. Dalla Dei Verbum a oggi (La tua Parola mi fa vivere 3), Cinisello Balsamo (Milano) 2008; S. PIÉ-NINOT, «De la Dei Verbum al Sínodo de los Obispos sobre la Palabra de Dios del 2008», Estudios Eclesiásticos 83 (2008) 219-222. 
presentación tuvo lugar en la tiempo que ella sea cada vez más el corazón de toda actividad eclesial» (núm. 1). El Papa siente la urgencia de dialogar con el mundo de hoy, «un mundo que considera con frecuencia a Dios como algo superfluo o extraño», y de darle una respuesta esperanzadora: «no hay prioridad más grande que ésta: abrir de nuevo al hombre de hoy el acceso a Dios, al Dios que habla y nos comunica su amor para que tengamos vida abundante» (n. 2).

\section{BREVE PRESENTACIÓn de LA VeRBum DOMinI}

El hilo conductor de la exhortación es el Prólogo del evangelio de Juan, texto que ofrece una síntesis de toda la fe cristiana: la Palabra, que en un principio estaba con Dios, se encarnó y vino a habitar en medio de nosotros. El documento se divide en tres partes principales: Verbum Dei (Jn 1, 1.14), Verbum in Ecclesia (Jn 1, 12) y Verbum mundo (Jn 1, 18), ilustradas con numerosas citas de los Padres de la Iglesia, de los documentos de la Pontificia Comisión Bíblica, de la Dei Verbum, de los escritos del Papa Juan Pablo II y, por supuesto, de los del actual pontífice. La primera parte es de gran densidad teológica, difícil de entender para las personas no especializadas, mientras las otras dos son de carácter más pastoral y contienen muchas propuestas concretas y actuales ${ }^{4}$.

Verbum Dei, la primera parte, aborda cuestiones de fondo como, por ejemplo, el uso analógico de la expresión Palabra de Dios. A este respecto, el documento insiste en el correcto uso de los términos Biblia, Escritura y Palabra de Dios, afirmando que el cristianismo no es «una religión del libro» sino «la religión de la $\mathrm{Pa}$ labra de Dios, del Verbo encarnado y vivo» (n. 7). Otras cuestiones tratadas son la dimensión cósmica y escatológica de la Palabra de Dios, la relación entre Tradición y Escritura, los conceptos de inspiración y verdad, entre otras. Ahora bien, uno de los argumentos que más interés suscitó en el Sínodo y que la exhortación recoge ampliamente (aprox. 40 páginas) -porque además es uno de los temas preferidos del Papa-, es la cuestión hermenéutica, es decir, la interpretación o exégesis de la Biblia en la Iglesia, sobretodo la que se realiza en ámbito académico ${ }^{5}$. Citando el documento de la Pontificia Comisión Bíblica La interpretación de la Biblia en la Iglesia (1993), el Papa recuerda que «los exegetas católicos no deben olvidar nunca que lo que interpretan es la Palabra de Dios. Su tarea no termina con la distinción de las fuentes, la definición de formas o la explicación de los procedimientos literarios. La meta de su trabajo se alcanza cuando aclaran el

4. En la citada rueda de prensa el Card. Gianfranco Ravasi definió el documento pontificio como «altamente teológico y pastoral».

5. Cuando el tema fue abordado en el Sínodo el 14 de octubre 2008, Benedicto XVI tomó la palabra e intervino en el debate (primera vez en la historia que esto sucedía): «Donde la exégesis no es teología, la Escritura no puede ser el alma de la teología y, viceversa, donde la teología no es esencialmente interpretación de la Escritura en la Iglesia, esta teología ya no tiene fundamento», explicitando una cuestión latente en el post-concilio. 
significado del texto bíblico como Palabra actual de Dios» (n. 33). Además de la dimensión teológica de los textos bíblicos, otras cuestiones que preocupan especialmente a Benedicto XVI son la armonía entre fe y razón, el dualismo y la hermenéutica secularizada como peligros a evitar, la necesidad de trascender «la letra» del texto y la unidad intrínseca de la Biblia.

Verbum in Ecclesia, la segunda parte, se concentra en la liturgia como lugar privilegiado de la Palabra de Dios. Después de tratar la relación entre la Palabra y los sacramentos, entre Palabra y Eucaristía, la sacramentalidad de la Palabra, la importancia del Leccionario..., Benedicto XVI aterriza en cuestiones prácticas como la formación de los lectores, la cual debe ser «bíblica, litúrgica y técnica» (n. 58), o la necesidad de mejorar la calidad de la homilía: «Debe quedar claro a los fieles que lo que interesa al predicador es mostrar a Cristo, que tiene que ser el centro de toda homilía. Por eso se requiere que los predicadores tengan familiaridad y trato asiduo con el texto sagrado» (n. 59). Recomienda además las celebraciones de la Palabra, redescubrir el valor del silencio, solemnizar la proclamación de la Palabra, cuidar la acústica de los edificios sagrados, no sustituir las lecturas litúrgicas con otros textos, utilizar el canto en los momentos adecuados, facilitar la participación al culto de las personas discapacitadas de la vista y el oído. Ministros ordenados, personas consagradas y fieles laicos todos están llamados a profundizar en su relación con Cristo, Palabra de Dios según su propio estado de vida (nn. 77-85). A esto hay que añadir su insistencia en la animación bíblica de toda la pastoral, sobre todo de la catequesis ${ }^{6}$ y de la lectio divina que, como recita el Mensaje final del Sínodo recogido en la exhortación, «es verdaderamente 'capaz de abrir al fiel no sólo el tesoro de la Palabra de Dios sino también de crear el encuentro con Cristo, Palabra divina y viviente'» (n. 87).

Verbum mundo, la tercera parte, se concentra en la misión que tiene la Iglesia de anunciar la Palabra de Dios al mundo, sobre todo a los jóvenes, los emigrantes, los enfermos y los pobres. El documento, por tanto, se sitúa en el surco de la nueva evangelización, prioridad de este pontificado, pues «tantos hermanos están bautizados, pero no suficientemente evangelizados. Con frecuencia, naciones un tiempo ricas en fe y vocaciones van perdiendo su propia identidad, bajo la influencia de una cultura secularizada» (n. 96). Esta nueva evangelización se realiza a través del testimonio: «la Palabra de Dios llega a los hombres por el encuentro con testigos que la hacen presente y viva» (n. 97). Y el testimonio abraza todas las dimensiones de la vida, incluyendo el compromiso por la justicia, la defensa de los derechos humanos, la promoción de la paz, la salvaguarda de la Creación, el encuentro con la cultura, la presencia en Internet para que en la red aparezca «el rostro de Cristo» y pueda «oírse su voz» (n. 113), y el diálogo interreligioso,

6. En todos sus niveles, la catequesis debe tomar como modelo la pedagogía de Jesús en el camino de Emaús. Cf. el documento de la V Conferencia General del Episcopado Latinoamericano, celebrada en Aparecida (Brasil) en 2007. 
pues «es de gran importancia que las religiones favorezcan en nuestras sociedades, con frecuencia secularizadas, una mentalidad que vea en Dios Todopoderoso el fundamento de todo bien, la fuente inagotable de la vida moral, sustento de un sentido profundo de hermandad universal» (n. 117).

Benedicto XVI concluye su exhortación apostólica recordando a todos los cristianos que «nuestra relación personal y comunitaria con Dios depende del aumento de nuestra familiaridad con la Palabra divina» (n. 121). Por ello, nos invita a hacer «silencio para escuchar la Palabra de Dios y meditarla, para que ella, por la acción eficaz del Espíritu Santo, siga morando, viviendo y hablándonos a lo largo de todos los días de nuestra vida (n. 124).

\section{La Palabra de Dios en la formación de los sacerdotes}

Antes de analizar más de cerca la Verbum Domini en lo referente a la Palabra de Dios en la vida sacerdotal, quisiera remontarme a los Lineamenta ( «líneas de orientación»), a partir de los cuales se elaboró el Instrumentum Laboris («documento de trabajo») que sirvió de base y punto de referencia durante la discusión sinodal $^{7}$. Una de las múltiples constataciones que emergieron de las respuestas a los Lineamenta fue que al hambre de la Palabra de Dios, que a menudo se percibe entre los fieles, no siempre corresponde una predicación adecuada de parte de los pastores, debido a carencias en la preparación recibida en el seminario o en el ejercicio pastoral. De ahí la necesidad de una «continua actualización formativa» para los que tienen una especial responsabilidad en el anuncio de la Palabra y para los candidatos al sacerdocio; más concretamente, se apuntaba a «un proyecto estratégico de formación» en vista a la predicación de la Palabra. Todas estas observaciones respondían al deseo de obtener un neto mejoramiento en las homilías, para lo cual son indispensables una mayor fidelidad al texto bíblico y una mayor atención a la condición de los fieles de parte del predicador.

Pues bien, estas constataciones, llegadas de las Iglesias particulares en todos los continentes ${ }^{8}$, fueron corroboradas por numerosas intervenciones (algunas, por cierto, acaloradas) de los padres sinodales ${ }^{9}$ y recogidas en las propuestas $n$. 15 (Actualización homilética y "Directorio sobre la homilía»), n. 31 (Palabra de Dios y presbíteros) y n. 32 (Formación de los candidatos al orden sagrado) que, junto con las demás, fueron entregadas a Benedicto XVI al final de los trabajos sinodales para su reflexión y elaboración de la exhortación apostólica.

7. La elaboración de ambos documentos corrió a cargo del Consejo de la Secretaría General del Sínodo con la ayuda de algunos expertos en la materia.

8. Respondieron a los Lineamenta y al relativo Cuestionario, la Iglesias Orientales Católicas sui iuris, las Conferencias Episcopales, los Dicasterios de la Curia Romana, la Unión de los Superiores Generales, obispos, sacerdotes, personas consagradas, teólogos y fieles laicos.

9. Son de destacar, a mi juicio, las de Mons. Ricardo Blázquez Pérez (España), Mons. Godfried Daneels (Bélgica) y Mons. Gerald F. Kicanas (Estados Unidos). 
Llegados a este punto, podemos ahora detenernos en la aportación de la Verbum Domini a este respecto, especialmente en dos puntos que retengo de importancia fundamental en la formación sacerdotal: el binomio estudio-oración y la debatida cuestión de la homilía.

\subsection{Estudio y oración}

El contacto con la Palabra de Dios es esencial e indispensable en la vida y en la misión del sacerdote (entiéndase de todo ministro ordenado): «Los obispos, presbíteros y diáconos no pueden pensar de ningún modo en vivir su vocación y misión sin un compromiso decidido y renovado de santificación, que tiene en el contacto con la Biblia uno de sus pilares» (Verbum Domini, 78). Estas palabras de Benedicto XVI no hacen sino confirmar las de su predecesor, el Papa Juan Pablo II, en su exhortación postsinodal Pastores dabo vobis, 26: «El sacerdote es, ante todo, ministro de la Palabra de Dios; es el ungido y enviado para anunciar a todos el Evangelio del Reino, llamando a cada hombre a la obediencia de la fe y conduciendo a los creyentes a un conocimiento y comunión cada vez más profundos del misterio de Dios, revelado y comunicado a nosotros en Cristo. Por eso, el sacerdote mismo debe ser el primero en tener una gran familiaridad personal con la Palabra de Dios: no le basta conocer su aspecto lingüístico o exegético, que es también necesario; necesita acercarse a la Palabra con un corazón dócil y orante, para que ella penetre a fondo en sus pensamientos y sentimientos y engendre dentro de sí una mentalidad nueva: «la mente de Cristo» (1 Cor 2, 16), de modo que sus palabras, sus opciones y sus actitudes sean cada vez más una transparencia, un anuncio y un testimonio del Evangelio. Solamente «permaneciendo» en la Palabra, el sacerdote será perfecto discípulo del Señor; conocerá la verdad y será verdaderamente libre, superando todo condicionamiento contrario o extraño al Evangelio (cf. Jn 8, 31-32)». Es precisamente este texto el que Benedicto XVI retoma en el $\mathrm{n} .80$ de la Verbum Domini ${ }^{10}$.

Ahora bien, la familiaridad con la Palabra no nace espontáneamente sino del contacto asiduo y amoroso con los textos. Hay que desearla, buscarla, cultivarla día a día, dedicarle tiempo, espacio y energía. No se improvisa ni se obtiene a toda prisa, al contrario crece y se desarrolla en la paz, el silencio, el estudio y la oración. La familiaridad con la Palabra abraza dos dimensiones fundamentales de la persona. Me refiero a la dimensión intelectual y a la espiritual, entre las cuales existe una relación de circularidad. No sin razón la Verbum Domini, cuando trata del papel de la Palabra de Dios en la vida espiritual de los candidatos al sacerdocio ministerial, habla de «relación entre el estudio bíblico y el orar con la Escritura» y más adelante menciona «la reciprocidad entre estudio y oración» (n. 82). Estudiar y orar son dos actividades contemplativas, en las que participa

10. Cf. el n. 79 (sobre los obispos), el n. 81 (sobre los diáconos). 
y se compromete «toda» la persona, es decir, esa unidad antropológica formada de mente, corazón y espíritu. Estudiar la Biblia científicamente nunca debiera ser un impedimento para rezar con ella y, viceversa, el orar con la Biblia nunca debiera negar o excluir su estudio riguroso.

El sacerdote es un servidor de la Palabra, pues su misión es darla a conocer a los fieles con sabiduría y generosidad. Así lo recordaba Juan Pablo II: «El sacerdote debe ser el primer 'creyente' de la Palabra, con la plena conciencia de que las palabras de su ministerio no son 'suyas', sino de Aquel que lo ha enviado. Él no es el dueño de esta Palabra: es su servidor. Él no es el único poseedor de esta Palabra: es deudor ante el Pueblo de Dios» (Pastores dabo vobis, 26). Por este motivo, Benedicto XVI insiste en que hay que proporcionar a los sacerdotes una sólida formación bíblica «para que puedan instruir al Pueblo de Dios en el conocimiento auténtico de las Escrituras» (Verbum Domini, 73). Esa formación no debería descuidar el Antiguo Testamento y sus páginas «difíciles y oscuras» a causa de la violencia (divina y humana) y la amoralidad de algunos de sus personajes ${ }^{11}$, pues los fieles necesitan ser guiados con competencia en la lectura y comprensión de la Biblia, especialmente cuando se trata de textos que pueden herir la sensibilidad de los lectores y lectoras actuales (n. 42).

\subsection{Homilía}

Si se tiene en cuenta que para mucha gente (me atrevería a decir la mayoría) la única ocasión de encontrarse directamente con la Palabra de Dios es la misa dominical (54 domingos al año), la homilía se convierte en un momento crucial para alimentar y estimular la vida de fe de los fieles a partir de la Escritura. El Sínodo habló de la homilía como «lugar de encarnación litúrgico y vital de la Palabra de Dios» (Propuesta n. 15) y la Verbum Domini la define como «una actualización del mensaje bíblico, de modo que se lleve a los fieles a descubrir la presencia y la eficacia de la Palabra de Dios en el hoy de la propia vida» (n. 59).

Ante la urgente necesidad de mejorar la calidad de las homilías ${ }^{12}$, Benedicto $\mathrm{XVI}$ alerta contra los sermones genéricos y abstractos y aquellas divagaciones inútiles más centradas en la figura y las dotes retóricas del predicador que en el mensaje de las lecturas litúrgicas. A estos ejemplos cabría añadir las homilías que se limitan a repetir el contenido del texto bíblico sin interpretarlo y, por supuesto, sin llegar al fondo del mensaje, las homilías que distraen al auditorio comentando los últimos acontecimientos políticos o sociales dejando de lado la Escritura o aquellas de tono moralizante que intentan sacudir la conciencia de los fieles apelando única y exclusivamente a la observancia o trasgresión de la

11. Cf. las aportaciones de J.-L. SKA, «Come leggere l'Antico Testamento», Civiltà Cattolica 3.435-3.436 (1993) 209-223; y mi conferencia «Leer hoy el Antiguo Testamento», pronunciada en la V Jornada Sacerdotal de la Provincia Eclesiástica de Barcelona, 5 de enero de 2009.

12. Cf. Sacramentum Caritatis, 46. 
ley. En todos los casos citados, se trata de homilías que no consiguen interpelar a los fieles en su vida fe. Palabras que no calan, no dejan huella. Palabras que resbalan por el micrófono sin llegar al corazón. Palabras, en definitiva, que no anuncian la Palabra. Algo falla, pues, en el proceso comunicativo.

La intervención en el Sínodo de Mons. Ricardo Blázquez, actual arzobispo de Valladolid, fue muy bien recibida en el aula. Tanto es así que sus palabras fueron retomadas literalmente en la Propuesta n. 15 y en la Verbum Domini, 59, donde el Papa aconseja a los predicadores que preparen la homilía en un clima de meditación y oración, para poder luego hablar «con convicción y pasión», y que además se planteen estas preguntas: «¿Qué dicen las lecturas proclamadas? ¿Qué me dicen a mí personalmente? ¿Qué debo decir a la comunidad, teniendo en cuenta su situación concreta?». Si el predicador quiere interpelar al auditorio con sus palabras, debe recordar que él es el primero que debe dejarse interpelar por la Palabra de Dios que está anunciando. Sólo así podrá establecer una comunicación auténtica, profunda y estimulante con los fieles.

Además de todo lo dicho, la homilía es un arte en el que se conjugan muchos factores: conocimientos bíblicos y teológicos, capacidad comunicativa, estrategias pedagógicas, testimonio de vida, entre otras. Comentar las lecturas litúrgicas con competencia y dinamismo y en un breve espacio de tiempo, actualizar su mensaje de forma vivencial y animar a los fieles a vivir su fe con esperanza es algo que se aprende con el estudio, la reflexión, la oración y la experiencia. Consciente de la dificultad de la tarea, Benedicto XVI pide a las autoridades competentes que elaboren un Directorio homilético con el fin de ayudar a los predicadores a ejercer mejor su ministerio (Verbum Domini, 60) ${ }^{13}$.

\section{La Palabra de Dios en la formación de las PERSONAS CONSAgRAdAS}

Si bien es verdad que "Palabra de Dios y vida consagrada» no fue un tema recurrente en el Sínodo ${ }^{14}$, estuvo presente en sus documentos de trabajo, en las discusiones de los círculos menores y en varias intervenciones de los padres sinodales ${ }^{15}$, de los auditores y auditoras.

En siete ocasiones el Instrumentum Laboris se refiere a la vida consagrada y en tres a las comunidades religiosas. Las personas consagradas viven una rela-

13. Entre otros subsidios litúrgicos, recomendamos Misa dominical publicada por el Centro de Pastoral Litúrgica de Barcelona. En cada volumen se prepara la liturgia de cuatro domingos a través de orientaciones para la celebración, notas exegéticas y proyecto de homilía.

14. Vale la pena recordar que, sin contar los padres sinodales, entre los que había 11 superiores generales (10 elegidos por la Unión de Superiores Mayores y el P. Alfonso Nicolás, Prepósito General de la Compañía de Jesús, nombrado por el Santo Padre), en el Sínodo han participado 16 religiosos (15 expertos y 1 auditor) y 13 religiosas (3 expertas y 10 auditoras).

15. El Card. Franc Rodé, cm, Prefecto de la Congregación para los institutos de vida consagrada y sociedades de vida apostólica, el P. José María Abella Batlle, cmf, Superior General 
ción directa con la Escritura que se alimenta cotidianamente de la Eucaristía y muy especialmente del rezo del Oficio Divino y la práctica de la Lectio Divina personal y comunitariamente. Este contacto asiduo con la Escritura ha de ser objeto de confrontación para un discernimiento personal y comunitario en vista de la evangelización. Según el n. 52 del Instrumentum Laboris -el único número totalmente dedicado al servicio de las personas consagradas-, «la lectura orante de la Palabra, hecha con jóvenes, es el camino para un renovado crecimiento vocacional y para un fecundo retorno al Evangelio y al espíritu de los fundadores, tanto auspiciado por el Concilio Vaticano II y recientemente propuesto por el Santo Padre Benedicto XVI a las personas de vida consagrada» ${ }^{16}$. Esta insistencia en la Lectio Divina o lectura orante también se vio reflejada en la exhortación postsinodal, especialmente en el n. 83, dedicado a la relación entre Palabra de Dios y vida consagrada, como veremos a continuación. Además de la Lectio Divina, dedicaremos un breve espacio a otros elementos importantes en la formación de las personas consagradas, a saber: el rezo de la liturgia de las horas, la piedad mariana y el anuncio de la Palabra en situaciones de frontera.

\subsection{Lectio Divina}

El mencionado n. 83 contiene una reflexión teológica, una recomendación y un agradecimiento. Inspirándose en la Propuesta 24 del Sínodo (2008), la exhortación apostólica post-sinodal Vita consecrata de Juan Pablo II (1996) y su instrucción Caminar desde Cristo: un renovado compromiso de la vida consagrada en el tercer milenio (2002), Benedicto XVI afirma que la vida consagrada «nace de la escucha de la Palabra de Dios y acoge el Evangelio como su norma de vida». Este modo de vivir siguiendo las huellas de Cristo se convierte en «'exégesis' viva de la Palabra de Dios» abierta a diversas expresiones y modalidades de las que dan testimonio los múltiples carismas que los fundadores y fundadoras han trasmitido. La recomendación del Papa se refiere a la práctica de la Lectio divina, vinculada desde sus inicios a la tradición monástica: «que nunca falte en las comunidades de vida consagrada una formación sólida para la lectura creyente de la Biblia». Por último, el agradecimiento va dirigido a la vida contemplativa, en manera especial a los monjes y monjas de clausura, que con su opción de vida, basada en la oración, la escucha y la meditación de la Palabra, «indican al mundo de hoy lo más importante, más aún, en definitiva, lo único decisivo: existe una razón última por la que vale la pena vivir, es decir, Dios y su amor inescrutable».

de los Misioneros Claretianos, el P. José Rodríguez Carballo, ofm, Ministro General de la Orden Franciscana de los Frailes Menores y el P. Joseph William Tobin, cssr, Superior General de la Congregación del Santísimo Redentor y actual arzobispo titular de Obba y Secretario de la Congregación para los institutos de vida consagrada y sociedades de vida apostólica.

16. Cf. su discurso en ocasión de la XII Jornada Mundial de la Vida Consagrada (2 de febrero de 2008). 
La amplia difusión en los cinco continentes de la Lectio Divina o lectura orante, inspirada en los Padres de la Iglesia y la tradición monástica (Regla de san Benito, 48) constituye un auténtico signo de esperanza para la Iglesia. Recordemos que el primero que sistematizó la Lectio Divina fue el cartujo de Grenoble, Guigo II, llamado el Angélico (†1188), con sus cuatro grados o etapas: lectio, meditatio, oratio y contemplatio. En la actualidad contamos con grandes especialistas, como el Card. Carlo M. Martini, Enzo Bianchi (prior de la comunidad de Bose), Carlos Mesters, Elena Bosetti, Giorgio Zevini, Bruno Secondin, Innocenzo Gargano, Dolores Aleixandre, Hilari Raguer, Florenci Costa, Tim Gray, Irene Novell, Kart Schultz, entre muchos otros ${ }^{17}$. Conscientes de la gran difusión actual de la Lectio Divina (cf. por ejemplo, los Seven Steps o «Siete pasos» en África, el compartir la Palabra en las comunidades de base...) y de otros métodos análogos (los ejercicios espirituales en la vida cotidiana, el método de revisión de vida de Acción Católica, el estudio del Evangelio de la comunidad del Prado, o la lectura bíblica de la fraternidad misionera «Verbum Dei», entre otros), las personas consagradas están llamadas a multiplicar esfuerzos en esta dirección. Una forma muy práctica y provechosa es realizar la lectura orante con los textos litúrgicos que la Iglesia propone para la celebración eucarística dominical y cotidiana. De este modo, se profundiza en la estrecha relación entre Palabra y Eucaristía, entre la mesa de la Palabra y la mesa de la Eucaristía ${ }^{18}$.

No podemos olvidar, además, que este contacto, personal y comunitario, con la Palabra de Dios puede suscitar en los jóvenes un deseo de consagración total: «Auténticas vocaciones a la vida consagrada y al sacerdocio encuentran terreno propicio en el contacto fiel con la Palabra de Dios» (Verbum Domini, 106).

\subsection{Liturgia de las horas y oración mariana}

Benedicto XVI exhorta a los consagrados y consagradas a ser «ejemplares en la celebración de la Liturgia de las Horas, de manera que puedan ser un punto de referencia e inspiración para la vida espiritual y pastoral de toda la Iglesia». El acento recae, pues, en el beneficio que el rezo de la liturgia de las horas proporciona al pueblo de Dios. Por este motivo, el Papa recomienda que las comunidades religiosas, en la medida de lo posible, «fomenten esta oración con la participación de los fieles» (Verbum Domini, 62).

Más adelante, en el n. 88, después de invitar a todos los fieles, principalmente en el ámbito familiar, a promover las oraciones marianas y en especial el Santo Rosario, Benedicto XVI se dirige a las comunidades de personas consagradas

17. La bibliografía sobre el tema es inmensa. Me limito a citar la serie "Tu Palabra es Vida» (publicada por la editorial Verbo Divino), compuesta de siete volúmenes preparados por Carlos Mesters y el equipo bíblico de la Conferencia de Religiosos de Brasil y adaptados por el equipo de biblistas de la Casa de la Biblia.

18. Sacramentum Caritatis, 66 y Verbum Domini, 86. 
exhortándolas a que sean fieles a la oración del Angelus Domini, que la tradición invita a recitar tres veces al día: al amanecer, al mediodía y al atardecer. Luego añade: «Esta práctica puede ayudarnos a reforzar un auténtico amor al misterio de la Encarnación».

\subsection{El anuncio de la Palabra en situaciones de frontera}

El punto de arranque de la Verbum Domini, 94 es la misión de anunciar la Palabra de Dios, una misión que comparten todos los discípulos y discípulas de Cristo. A continuación especifica en qué consiste concretamente esta misión para los obispos, los sacerdotes, los diáconos, las personas consagradas y los laicos. Por lo que se refiere a las personas consagradas, el Papa, retomando la instrucción Caminar desde Cristo, afirma: «La vida consagrada brilla en toda la historia de la Iglesia por su capacidad de asumir explícitamente la tarea del anuncio y la predicación de la Palabra de Dios, tanto en la missio ad gentes como en las más difíciles situaciones, con disponibilidad también para las nuevas condiciones de evangelización, emprendiendo con ánimo y audacia nuevos itinerarios y nuevos desafíos para anunciar eficazmente la Palabra de Dios».

La lectura de estas palabras me ha hecho recordar la intervención en el Sínodo de Mons. Joseph William Tobin, cssr, sobre la vida consagrada como obediencia radical a la Palabra de Dios, tema que desarrolló en tres momentos: obediencia a la Palabra hecha carne en Jesucristo, obediencia a la Palabra que habla por medio de los signos de los tiempos y los lugares, y-en fin-obediencia a la Palabra aprendida a través del sufrimiento. En este último punto, el más conmovedor de su intervención, J. W. Tobin recordó a tantos consagrados y consagradas que viven la obediencia en medio de grandes sufrimientos. Recordó a las religiosas que, muy recientemente, han sido víctimas de violencia y de abusos sexuales en India. Recordó a los agentes pastorales que trabajan secretamente en favor de los refugiados en regímenes totalitarios. Recordó a las personas consagradas que, abandonando su lengua, cultura e historia, llevan a cabo la primera evangelización en muchas partes del mundo. Recordó a las personas consagradas ancianas y enfermas que son signos de esperanza en un mundo que invita a la desesperación. Finalmente, recordó a los consagrados y consagradas que acompañan a los que no son importantes ni poderosos, así como a aquellos que sufren la dolorosa experiencia de ser marginados en su Iglesia local.

La misión de la persona consagrada es, qué duda cabe, una misión profética que la coloca a menudo en situaciones de frontera, donde se ve obligada a luchar contra el miedo, la oposición, las dificultades, el sufrimiento y la injusticia con la fuerza liberadora de la Palabra. La Palabra inspira, sostiene y fortalece a los consagrados y consagradas y al mismo tiempo les da la fuerza, la valentía y la creatividad necesarias para seguir difundiendo la Buena Noticia allí donde 
son llamados, donde quiera que sea. Apreciamos las palabras de Benedicto XVI que da gracias a Dios: «por estos testimonios espléndidos, a menudo escondidos, de tantos cristianos -sacerdotes, religiosos y laicos- que han prestado y siguen prestando sus manos, sus ojos y su corazón a Cristo, verdadero médico de los cuerpos y las almas!» (Verbum Domini, 106).

\section{CONCLUSIÓN}

Quisiera terminar esta reflexión sobre la Palabra de Dios en la formación de los sacerdotes y las personas consagradas a la luz del Sínodo de la Palabra y de exhortación apostólica post-sinodal Verbum Domini con unas palabras de Benedicto XVI en la conclusión de la misma: «Deseo exhortar una vez más a todo el Pueblo de Dios, a los Pastores, a las personas consagradas y a los laicos a esforzarse para tener cada vez más familiaridad con la Sagrada Escritura. Nunca hemos de olvidar que el fundamento de toda espiritualidad cristiana auténtica y viva es la Palabra de Dios anunciada, acogida, celebrada y meditada en la Iglesia. Esta relación con la divina Palabra será tanto más intensa cuanto más seamos conscientes de encontrarnos ante la Palabra definitiva de Dios sobre el cosmos y sobre la historia, tanto en la Sagrada Escritura como en la Tradición viva de la Iglesia» (n. 121).

Ciertamente estas palabras nos interpelan a todos. Todos somos, y debemos sentirnos, responsables de la misión de anunciadores y anunciadoras de la Palabra, cada persona desde su estado de vida y desde su ámbito específico de participación en la vida eclesial. Y -qué duda cabe- Verbum Domini interpela de manera especial a los formadores y formadoras en los seminarios y casas religiosas, pues tienen bajo su cuidado el futuro de la Iglesia. Ellos y ellas están llamados a hacer todo lo que esté en sus manos para que la Palabra de Dios ocupe el centro de sus vidas y el de sus jóvenes aspirantes a la vida sacerdotal y consagrada. Estudio, oración, testimonio de vida, anuncio de la Palabra y misión de frontera son los puntales que ningún educador y educadora pueden descuidar en su programa. 